\title{
The Personality Factors Predictors in Substance Abuse Among Iranian College Students
}

\author{
Farzad Jalilian, ${ }^{1}$ Behzad Karami Matin, ${ }^{1}$ Mohammad Ahmadpanah, ${ }^{2}$ Mari Ataee, ${ }^{3}$ Mehdi Mirzaei \\ Alavijeh, ${ }^{4}$ Ahmad Ali Eslami, ${ }^{5,}{ }^{*}$ and Touraj Ahmadi Jouybari ${ }^{3}$ \\ ${ }^{1}$ Research Center for Environmental Determinants of Health, Kermanshah University of Medical Sciences, Kermanshah, IR Iran \\ ${ }^{2}$ Behavioral Disorders and Substances Abuse Research Center, Hamadan University of Medical Sciences, Hamadan, Iran \\ ${ }^{3}$ Substance Abuse Prevention Research Center, Kermanshah University of Medical Sciences, Kermanshah, IR Iran \\ ${ }^{4}$ Department of Public Health, School of Health, Kermanshah University of Medical Sciences, Kermanshah, IR Iran \\ ${ }^{5}$ Department of Health Education and Promotion, School of Health, Isfahan University of Medical Sciences, Isfahan, IR Iran \\ Corresponding author: Ahmad Ali Eslami, Department of Health Education and Promotion, School of Health, Isfahan University of Medical Sciences, Isfahan, IR Iran. Tel: \\ +98-3137923242, Fax: +98-3136682509, E-mail: Eslami@HLTH.mui.ac.ir; eslamiaa@gmail.com
}

Received 2015 January 23; Revised 2015 November 17; Accepted 2015 November 18.

\begin{abstract}
Background: A major issue to consider in high risk behaviors such as substance abuse is personality factors.

Objectives: This study aimed to determine the role of personality factors (anxiety sensitivity, sensation seeking, hopelessness, and impulsivity) in substance use, psychotropic drug use, smoking, and alcohol drinking in a sample of male medical students in Iran. Patients and Methods: In this cross-sectional study, conducted in Isfahan and Kermanshah Medical Universities in Iran, a total of 425 male medical students were randomly selected with the proportional to size from different faculties to participate voluntarily in the study. A self-report written questionnaire was applied to collect data. Then, the obtained data were analyzed by SPSS version 20 using logistic regression statistical tests at 95\% significant level.

Results: Our findings showed that hopelessness $(\mathrm{OR}=1.095,95 \% \mathrm{CI}: 1.033,1.160)$ and sensation seeking $(\mathrm{OR}=1.139,95 \% \mathrm{CI}: 1.065,1.219)$ were the main influential predictors on smoking. Anxiety sensitivity ( $\mathrm{OR}=1.436,95 \% \mathrm{CI}: 1.114,1.851)$ and impulsively $(\mathrm{OR}=1.443,95 \%$ CI: $1.153,1.806)$ were the main influential predictors on drug abuse. In addition, anxiety sensitivity (OR $=1.460,95 \% \mathrm{CI}: 1.004,2.124)$ and sensation seeking $(\mathrm{OR}=1.756,95 \% \mathrm{CI}: 1.120,2.753)$ were the main influential predictors on psychotropic drug abuse. Finally, sensation seeking $(\mathrm{OR}=1.222$, $95 \% \mathrm{CI}: 1.121,1.331)$ was the main influential predictor on alcohol drinking.

Conclusions: Our findings indicated that sensation seeking was the best predictor for alcohol drinking, cigarette smoking, and psychotropic drug abuse.
\end{abstract}

Keywords: Alcohol Drinking, Smoking, Drug Abuse, Psychotropic Drugs, Universities

\section{Background}

Addiction is a disorder with clinical, behavioral, and cognitive symptoms affected by social, psychological, biological, and pharmacological factors; social factors mostly affect onset of substance abuse and biological factors are responsible for maintenance of substance abuse (1). In spite of the obvious risks and complications of addiction, its victims increase every day and reports by international organizations indicate the rise of substance abuse all over the world (2). Developing countries has been known to be at higher risk of substance abuse due to their large youth population, where college students like other groups are not supported against the risky factors (3). Substance abuse is one of the psychological problems among college students (4). Considering several educational and noneducational side consequences of substance abuse, such as lack of motivation, education failure, physical and mental problems, suicide and aggressive behaviors, lack of iden- tity, and risky sexual behaviors among college students, it seems necessary to design and implement preventive interventions $(3,5)$. A major issue in designing preventive interventions is to gain knowledge on the effects of personality factors on predicting substance abuse. In this regard, several studies investigated the association of personality factors such as anxiety, depression, impulsivity, and sensation seeking with substance abuse (6-12). For example, Wills emphasized the effects of personality factors, especially sensation seeking, on substance abuse (6). Grant et al. reported the relationship between alcohol drinking and personality factors of anxiety and depression (7). Ersche and Kopstein also showed that high rates of sensation seeking increases probability of substance abuse $(8,9)$. In addition, some other studies mentioned the role of poor impulsive control in substance abuse $(10,11)$. In this regard, Malmberg et al. introduced sensation seeking and impulsivity as strong factors to predict substance abuse, though 
they rejected the relationship between anxiety and substance abuse (12). On the other hand, several studies suggested higher rates of substance abuse among men compared to women which shows the importance of considering gender in studies on substance abuse $(13,14)$. It seems that knowledge of behavioral science experts on personality factors which predict substance abuse could help planning preventive interventions (6-12).

\section{Objectives}

Regarding the absence of related studies in developing countries, our study focused on personality traits related to drug abuse, psychotropic drug use, smoking, and alcohol drinking in a sample of male medical students in Iran.

\section{Patients and Methods}

\subsection{Participants and Procedure}

The study was a part of a project conducted among male medical students in Kermanshah and Isfahan Medical Universities during 2014 - 2015, with the goal of providing knowledge for the prevention of the substance abuse. The first part of project was a cross-sectional study conducted on 425 male college students in two Kermanshah and Isfahan Medical Universities during 2014. The sample size of 425 was calculated at 95\% significant level according to the results of the previous study (15) and considering $20 \%$ attrition rate. Omitting the incomplete questionnaires, 355 questionnaire were analyzed (response rate was $84 \%$ ). To enroll the participants and collect data, the following stages were taken. First, each faculty in 2 medical universities in Iran was considered as a class (category). Then, proportional to the number of male students in each faculty (medical, dentist, pharmacy, health and nutrition, paramedical, and nursing), participants were randomly enrolled in the study. Finally, the volunteers were given the self-questionnaire. This study was approved by Isfahan University of Medical Sciences' institutional review board and informed consents were obtained from all participants. In addition, Ethics Committee of Isfahan Medical Science University approved the study.

\subsection{Measures}

The questionnaire used in the study comprised 3 parts which are discussed below.

\subsubsection{Demographic Characteristics}

Demographic information, including age, marital status, parents' educational status, having a drug abuser friend, having a drug abuser family, living in dormitory, and parents' divorce was evaluated in this part.

\subsubsection{Substance Abuse}

This part includes 4 questions to assess the respondents' history of drug abuse (opium, crack, heroin), psychotropic drug abuse (methamphetamine, ecstasy, LSD), alcohol drinking or cigarettes smoking. One question for each category was asked as follows: "Have you consumed drug abuse/psychotropic drug abuse/alcoholic drinks/cigarettes smoking during the past 3 months?" The reply options for each question was "Yes" or "No".

\subsubsection{Personality Factors Scale}

The personality factors were measured by a standard scale, including 28 items (16), which were composed of 4 major constructs of 1) anxiety sensitivity, 2) sensation seeking, 3) hopelessness, and 4) impulsivity. Prior to conducting the main project, a pilot study was done to assess the utility of the instrument. The pilot study participants were 18 male medical students, similar to those who participated in the main study. It was conducted to obtain feedback about the clarity, length, comprehensiveness, and completion time of the various instruments as well as collecting data to estimate the internal consistency of the measures. It should be noted that the validity of the questionnaire was approved by an expert plan (comprising of a psychologist, a sociologist, a health educator, and an addiction expert).

Seven items were designed to measure anxiety sensitivity e.g., "It frightens me when I feel my heart beat change". Seven items were designed to measure sensation seeking e.g., "I am interested in experience for its own sake even if it is illegal". Eight items were designed to measure hopelessness e.g., "I feel that I'm a failure". Six items were designed to measure impulsively e.g., "I feel I have to be manipulative to get what I want”. In order to facilitate the participants' responses to the items, they were standardized based on Likert scale, selecting 1 of 4 response options ( $1=$ strongly disagree, 2 = disagree, $3=$ agree, and $4=$ strongly agree). The reliability coefficients for the abovementioned constructs in our pilot study were as follows: anxiety sensitivity, $\alpha=0.71$; sensation seeking, $\alpha=0.75$; hopelessness, $\alpha$ $=0.80 ;$ and impulsively, $\alpha=0.72$.

\subsection{Statistical Analysis}

The data were analyzed by SPSS software for Windows (ver. 20). Descriptive statistics were used to summarize and organize the demographic data. Backward stepwise multiple logistic regression analysis was performed to predict the personality factors on substance abuse. Results of logistic models were expressed as ORs with 95\% CIs. The level of significance was $(\mathrm{P}<0.05)$. The Cronbach Coefficient $\alpha$ was used to estimate the internal consistency of the various measures 


\section{Results}

The mean age of participants was 19.9 years (95\% CI: 19.79, 20.04), ranged from 18 to 22 years. Almost, $95.2 \%$ of respondents were single. In addition, $19.4 \%, 3.9 \%, 1.1 \%$, and $10.1 \%$ of the participants had respectively the history of smoking, drug abuse, psychotropic drug abuse, and alcohol consumption during the past 3 months.

Backward stepwise multiple logistic regression analysis was conducted for the prediction role of personality factors on substance abuse. Based on our findings regarding smoking, drug abuse, and psychotropic drug abuse, the best model was selected in the third step and for alcohol drinking the best model was selected in the fourth step(Tables 1 - 4).

Table 1 indicates that the hopelessness $(\mathrm{OR}=1.095,95 \%$ CI: $1.033,1.160)$, and sensation seeking $(\mathrm{OR}=1.139,95 \% \mathrm{CI}$ : $1.065,1.219)$ were the main influential predictors on smoking.

Table 2 shows that the anxiety sensitivity $(\mathrm{OR}=1.436$, 95\% CI:1.114, 1.851), and impulsively (OR=1.443, 95\% CI: 1.153 , 1.806) are the main influential predictors on drug abuse.

Table 3 shows that among the personality factors, the anxiety sensitivity ( $\mathrm{OR}=1.460,95 \% \mathrm{CI}: 1.004,2.124)$, and sensation seeking ( $\mathrm{OR}=1.756,95 \% \mathrm{CI}: 1.120,2.753)$ were the main influential predictors on psychotropic drug.

Finally, our result showed that the sensation seeking $(\mathrm{OR}=1.222$, 95\% CI:1.121, 1.331) was the main influential predictor on alcohol drinking among the participants (Table 4).

\section{Discussion}

The main goal of our study was to determine a typology for classifying substance abusers based on personality factors. Our study indicated that anxiety sensitivity could be a predicator of drug abuse and psychotropic drugs abuse. Buckner et al. also showed the relationship between anxiety sensitivity and using marijuana (17). Furthermore, Lejuez et al. reported greater heroin use among participants with high anxiety sensitivity (18). Anxiety sensitivity is a cognitive, individual difference variable that refers to the fear of arousal-related bodily sensations (19). Regarding the effect of anxiety sensitivity on predicting opium and psychotropic drug abuse, it seems necessary to consider and suggest solutions to control anxiety sensitivity among college students. A commonly suggested solution to control anxiety sensitivity is relaxation, reported to be effective by several studies (20-22). Therefore, we recommend that counseling centers design and implement related training programs in universities.
Another finding of our study was that sensation seeking could predict smoking (OR: 1.139), psychotropic drugs (OR:1.756), and alcohol drinking (OR:1.222), which suggest its more prediction value than other personality factors. Sensation seeking is a personality trait believed to have a biological basis expressed as a need for physiological arousal, novel experience, and willingness to take social, physical, and financial risks (to obtain such arousal) (23). Sensation seekers explore such environments which offer them opportunities on illegal provocations and joining deviant peer groups (24). Several studies indicated that sensation seeking was associated with several illegal and risky behaviors such as alcohol consumption, drug abuse, unprotected sex, and violent behaviors (25-27). On one hand, Bancroft et al. stated that sensation seeking increases risk taking among the youth to gain joy, which lead them to consume drug and alcohol and further feel the joy and fix the uniformity. On the other hand, they might underestimate the danger and negative consequences of risky behaviors in their lives (27). In addition, Woicik et al. and Brunelle et al. in their studies reported sensation seeking as a major factor to predict alcohol consumption $(28,29)$. Sensation seekers always find themselves in risk settings. Although these people are aware of the risk, they still believe that they need a certain level of danger to live happily (30). Our findings showed that it is essential to consider sensation seeking while designing and developing training and preventive programs to substance abuse and control of sensation seeking among young adults. Developing alternative environments such as sport complexes (including exciting sports) and guiding youth mental power to friendly routes through group activities such as social and political activities, festivals as well as local and group competitions could be efficient to deplete youth excitement.

Hopelessness is another personality factor investigated in the present study. In this respect, our results showed that hopelessness was a predicator to cigarette smoking $(\mathrm{OR}=1.095)$. One of the underlying factors of the risky behavior is hopelessness, defined as a system of negative expectations concerning oneself and one's future life and also an important concern in health and social care (31, 32). Researchers believe that people smoke to feel happier and improve their mood (33). The present study results show that hopelessness is a predicting factor to smoking. Therefore, providing counseling centers and psychological services could help in on time recognition and treatment of mental health problems. Holding religious and national festivals and celebrations, planning trips and improving students' participation in cultural, educational, recreational, and sport programs could improve and solve students' temper and mental problems, while reduce their hopelessness. All these eventually help decrease smoking 
Table 1. Logistic Regression Analysis of Variables Related to Smoking

\begin{tabular}{|c|c|c|c|c|}
\hline \multirow[t]{2}{*}{ Variable } & \multirow[t]{2}{*}{ Odds Ratio } & \multicolumn{2}{|c|}{ 95\% CI } & \multirow[t]{2}{*}{ P Value } \\
\hline & & Lower & Upper & \\
\hline Hopelessness & 1.095 & 1.033 & 1.160 & 0.002 \\
\hline Sensation seeking & 1.139 & 1.065 & 1.219 & 0.001 \\
\hline Final model: Step 3 & & - & - & - \\
\hline
\end{tabular}

Table 2. Logistic Regression Analysis of Variables Related to Drug Abuse

\begin{tabular}{|c|c|c|c|c|}
\hline \multirow[t]{2}{*}{ Variable } & \multirow[t]{2}{*}{ Odds Ratio } & \multicolumn{2}{|c|}{ 95\% CI } & \multirow[t]{2}{*}{ P Value } \\
\hline & & Lower & Upper & \\
\hline Anxiety sensitivity & 1.436 & 1.114 & 1.851 & 0.005 \\
\hline Impulsively & 1.443 & 1.153 & 1.806 & 0.001 \\
\hline Final model: Step 3 & - & - & - & - \\
\hline
\end{tabular}

Table 3. Logistic Regression Analysis of Variables Related to Psychotropic Drug Abuse

\begin{tabular}{|c|c|c|c|c|}
\hline \multirow[t]{2}{*}{ Variable } & \multirow[t]{2}{*}{ Odds Ratio } & \multicolumn{2}{|c|}{ 95.0\% CI } & \multirow[t]{2}{*}{ P Value } \\
\hline & & Lower & Upper & \\
\hline Sensation seeking & 1.460 & 1.004 & 2.124 & 0.048 \\
\hline Final model: Step 4 & 1.756 & 1.120 & 2.753 & -0.048 \\
\hline Final model: Step 3 & - & - & - & - \\
\hline
\end{tabular}

Table 4. Logistic Regression Analysis of Variables Related to Alcohol Drinking

\begin{tabular}{lccc}
\hline Variable & Odds Ratio & & 95.0\% CI \\
\cline { 2 - 4 } & & Lower & Upper \\
\hline Sensation seeking & 1.222 & 1.121 & 0.001 \\
Final model: Step 4 & - & - & - \\
\hline
\end{tabular}

rates among college students.

Finally our findings indicated impulsivity as a significant predicator to opium abuse $(\mathrm{OR}=1.443)$. Impulsivity includes a wide range of behaviors, being mostly ignored, which are done immaturely for gaining a reward or joy, entailing high risk, and lead to significant undesirable consequences (34). Also, behaviorists define impulsivity as gaining short-term benefits, even if they are worthless, instead of long-term worthy achievements (35). Impulsive behaviors are precipitance, unplanned, and error prone (36). Epstein et al. in their study reported the effects of impulsivity on substance abuse (37). It seems that tendency to solve problems while not considering its negative consequences and acting impulsively to face life events could be some predicators to substance abuse. In this respect, training of coping strategies could be beneficial and result in helpful solutions to prevent substance abuse among college students. Therefore, educational researchers have suggested problem solving and define it as a coping strategy to improve personal and social abilities and to decrease tensioning and psychopathological symptoms (38). This could be effective on avoiding substance abuse among college students.

Knowledge of behavior factors predictors could facilitate designing and implementing behavior change interventions. Our findings suggested that personality factors are effective predictors to substance abuse. Furthermore, sensation seeking is the best predictor for alcohol drinking, cigarette smoking, and psychotropic drug abuse. In conclusion, considering relevant personality fac- 
tors would result in designing efficient preventive interventions.

\section{Acknowledgments}

This article is a part of the PhD dissertation on health, education, and promotion supported by Isfahan University of Medical Sciences. We would like to thank Deputy of Research of Isfahan University of Medical Sciences for financial support.

\section{Footnotes}

Authors' Contribution: Farzad Jalilian, Ahmad Ali Eslami, and Mehdi Mirzaei Alavijeh developed the study concept, the protocol, and design, as well as data analyses; Behzad Karami Matin and Mohammad Ahmadpanah participated in designing educational program; Mari Ataee and Touraj Ahmadi Jouybari participated in writing manuscript. All authors provided comments and approved the final manuscript. The authors declared no conflict of interest.

Funding/Support: This study was funded by the deputy of research of Isfahan University of Medical Sciences.

\section{References}

1. Ahmadpanah M, Mirzaei Alavijeh M, Allahverdipour H, Jalilian F, Haghighi M, Afsar A, et al. Effectiveness of Coping Skills Education Program to Reduce Craving Beliefs among Addicts Referred To Addiction Centers in Hamadan: A Randomized Controlled Trial. Iran JPublic Health. 2013;42(10):1139-44. [PubMed: 26060622].

2. Matin BK, Jalilian F, Alavije MM, Ashtarian H, Mahboubi M, Afsar A. Using the PRECEDE model in understanding determinants of quality of life among Iranian male addicts. Glob J Health Sci. 2014;6(6):19-27. doi: 10.5539/gjhs.v6n6p19. [PubMed: 25363110].

3. Barati M, Allahverdipour H, Jalilian F. [Prevalence and predictive factors of psychoactive and hallucinogenic substance abuse among college students].J Fundament Mental Health. 2012;13(4):374-83.

4. Monirpoor N, Khoosfi H, Gholamy Zarch M, Tamaddonfard M, Tabatabaei Mir SF, Mohammad Alipour M, et al. Vulnerability to substance abuse and the risk of suicide in students of region 12 of islamic azad university. Int J High Risk Behav Addict. 2014;3(2):ee11229. doi: 10.5812/ijhrba.11229. [PubMed: 25032157].

5. Jalilian F, Karami Matin B, Ahmadpanah M, Ataee M, Ahmadi Jouybari T, Eslami AA, et al. Socio-demographic characteristics associated with cigarettes smoking, drug abuse and alcohol drinking among male medical university students in Iran. J Res Health Sci. 2015;15(1):42-6. [PubMed: 25821025].

6. Wills TA, Windle M, Cleary SD. Temperament and novelty seeking in adolescent substance use: convergence of dimensions of temperament with constructs from Cloninger's theory. J Pers Soc Psychol. 1998;74(2):387-406. [PubMed: 9491584].

7. Grant VV, Stewart SH, O'Connor RM, Blackwell E, Conrod PJ. Psychometric evaluation of the five-factor Modified Drinking Motives Questionnaire-Revised in undergraduates. Addict Behav. 2007;32(11):2611-32. doi: 10.1016/j.addbeh.2007.07.004. [PubMed: 17716823].
8. Ersche KD, Turton AJ, Pradhan S, Bullmore ET, Robbins TW. Drug addiction endophenotypes: impulsive versus sensationseeking personality traits. Biol Psychiatry. 2010;68(8):770-3. doi: 10.1016/j.biopsych.2010.06.015. [PubMed: 20678754].

9. Kopstein AN, Crum RM, Celentano DD, Martin SS. Sensation seeking needs among 8th and 11th graders: characteristics associated with cigarette and marijuana use. Drug Alcohol Depend. 2001;62(3):195-203. [PubMed: 11295324].

10. Botvin GJ, Griffin KW, Paul E, Macaulay AP. Preventing Tobacco and Alcohol Use Among Elementary School Students Through Life Skills Training. Journal of Child \& Adolescent Substance Abuse. 2003;12(4):117. doi:10.1300/J029v12n04_01.

11. Epstein JA, Griffin KW, Botvin GJ. A model of smoking among innercity adolescents: the role of personal competence and perceived social benefits of smoking. Prev Med. 2000;31(2 Pt 1):107-14. doi: 10.1006/pmed.2000.0674. [PubMed: 10938210].

12. Malmberg M, Kleinjan M, Overbeek G, Vermulst AA, Lammers J, Engels RC. Are there reciprocal relationships between substance use risk personality profiles and alcohol or tobacco use in early adolescence?. Addict Behav. 2013;38(12):2851-9. doi: 10.1016/j.addbeh.2013.08.003. [PubMed: 24018230].

13. King KM, Chassin L. A prospective study of the effects of age of initiation of alcohol and drug use on young adult substance dependence. J Stud Alcohol Drugs. 2007;68(2):256-65. [PubMed: 17286344].

14. Hussong AM, Chassin L. Stress and coping among children of alcoholic parents through the young adult transition. Dev Psychopathol. 2004;16(4):985-1006. [PubMed: 15704824].

15. Rezakhani Moghadam H, Shojaeizadeh D, Lashgarara B, Safari H, Taghi Savadpour M, Sohbatzadeh R. [Comparison of Substance Abuse and its Causes among Students of Tehran University of Medical Sciences and University of Tehran].J Health Sys Res. 2013;8(7):1300-10.

16. Conrod PJ, Pihl RO, Stewart SH, Dongier M. Validation of a system of classifying female substance abusers on the basis of personality and motivational risk factors for substance abuse. Psychol Addict Behav. 2000;14(3):243-56. [PubMed: 10998950].

17. Buckner JD, Zvolensky MJ, Smits JA, Norton PJ, Crosby RD, Wonderlich $\mathrm{SA}$, et al. Anxiety sensitivity and marijuana use: an analysis from ecological momentary assessment. Depress Anxiety. 2011;28(5):420-6. doi: 10.1002/da.20816. [PubMed: 21449005].

18. Lejuez CW, Paulson A, Daughters SB, Bornovalova MA, Zvolensky MJ. The association between heroin use and anxiety sensitivity among inner-city individuals in residential drug use treatment. Behav Res Ther. 2006;44(5):667-77. doi: 10.1016/j.brat.2005.04.006. [PubMed: $16002042]$.

19. DeMartini KS, Carey KB. The role of anxiety sensitivity and drinking motives in predicting alcohol use: a critical review. Clin Psychol Rev. 2011;31(1):169-77. doi: 10.1016/j.cpr.2010.10.001. [PubMed: 21074306].

20. Norton PJ. A randomized clinical trial of transdiagnostic cognitve-behavioral treatments for anxiety disorder by comparison to relaxation training. Behav Ther. 2012;43(3):506-17. doi: 10.1016/j.beth.2010.08.011. [PubMed: 22697440].

21. Cramer H, Lauche R, Langhorst J, Dobos G. Yoga for depression: a systematic review and meta-analysis. Depress Anxiety. 2013;30(11):106883. doi: 10.1002/da.22166. [PubMed: 23922209].

22. Kao P-C, Craigie P. Coping Strategies of Taiwanese University Students as Predictors of English Language Learning Anxiety. Social Behav Personal Int J. 2013;41(3):411-9. doi: 10.2224/sbp.2013.41.3.411.

23. Stephenson MT, Hoyle RH, Palmgreen P, Slater MD. Brief measures of sensation seeking for screening and large-scale surveys. Drug Alcohol Depend. 2003;72(3):279-86. [PubMed: 14643945].

24. Caspi A, Roberts BW, Shiner RL. Personality development: stability and change. Annu Rev Psychol. 2005;56:453-84. doi: 10.1146/annurev.psych.55.090902.141913. [PubMed: 15709943]. 
25. Lau-Barraco C, Skewes MC, Stasiewicz PR. Gender differences in high-risk situations for drinking: are they mediated by depressive symptoms?. Addict Behav. 2009;34(1):68-74. doi: 10.1016/j.addbeh.2008.09.002. [PubMed:18940274].

26. Reed E, Amaro H, Matsumoto A, Kaysen D. The relation between interpersonal violence and substance use among a sample of university students: examination of the role of victim and perpetrator substance use. Addict Behav. 2009;34(3):316-8. doi: 10.1016/j.addbeh.2008.10.015. [PubMed: 19028021].

27. Bancroft J, Janssen E, Strong D, Carnes L, Vukadinovic Z, Long JS. Sexual risk-taking in gay men: the relevance of sexual arousability, mood, and sensation seeking. Arch Sex Behav. 2003;32(6):555-72. [PubMed: 14574099].

28. Woicik PA, Stewart SH, Pihl RO, Conrod PJ. The Substance Use Risk Profile Scale: a scale measuring traits linked to reinforcementspecific substance use profiles. Addict Behav. 2009;34(12):1042-55. doi: 10.1016/j.addbeh.2009.07.001. [PubMed: 19683400].

29. Brunelle C, Assaad JM, Barrett SP, Vila C , Conrod PJ, Tremblay RE, et al. Heightened heart rate response to alcohol intoxication is associated with a reward-seeking personality profile. Alcohol Clin Exp Res. 2004;28(3):394-401. [PubMed: 15084896].

30. Castellanos-Ryan N, O'Leary-Barrett M, Sully L, Conrod P. Sensitivity and specificity of a brief personality screening instrument in predicting future substance use, emotional, and behavioral problems: 18-month predictive validity of the Substance Use Risk Profile Scale. Alcohol Clin Exp Res. 2013;37 Suppl 1:E281-90. doi: 10.1111/j.15300277.2012.01931.x. [PubMed: 22974180].
31. Yip PS, Cheung YB. Quick assessment of hopelessness: a crosssectional study. Health Qual Life Outcomes. 2006;4:13. doi:10.1186/14777525-4-13. [PubMed: 16509984].

32. Nigar P, Derman MT, Sadoglu O. The levels of anxiety and hopelessness of primary education children with speech disorders and of their parents. Element Educat Online. 2010;9(1):23-30.

33. Snyder CR. Handbook of hope: Theory, measures, and applications. Academic press; 2000.

34. van Gaalen MM, van Koten R, Schoffelmeer AN, Vanderschuren LJ Critical involvement of dopaminergic neurotransmission in impulsive decision making. Biol Psychiatry. 2006;60(1):66-73. doi: 10.1016/j.biopsych.2005.06.005. [PubMed: 16125144].

35. Petry NM. Substance abuse, pathological gambling, and impulsiveness. Drug Alcohol Depend. 2001;63(1):29-38. [PubMed: 11297829].

36. Lovic V, Saunders BT, Yager LM, Robinson TE. Rats prone to attribute incentive salience to reward cues are also prone to impulsive action. Behav Brain Res. 2011;223(2):255-61. doi:10.1016/j.bbr.2011.04.006. [PubMed: 21507334].

37. Epstein JA, Botvin GJ, Diaz T, Williams C, Griffin KW. Aggression, Victimization and Problem Behavior Among Inner-City Minority Adolescents. J Child Adole Subs Abuse. 2000;9(3):51-66. doi: 10.1300/J029v09n03_04.

38. Barati M, Allahverdipour H, Moeini B, Farhadi Nasab A, Mahjub H, Jalilian F. [Evaluation of Problem Solving Skills Training (P.S.S.T) on College Students' Perceived Behavioral Control against Psychoactive Drug abuse]. Toloe Behdasht. 2011;10(2):81-93. 